\title{
O Ciclo das Commodities e Crescimento Regional Desigual no Brasil: uma aplicação de Equilíbrio Geral Computável (EGC)
}

\author{
Área 4.2: Economias Regionais e Urbanas
}

\author{
Celso Bissoli Sessa ${ }^{1}$ \\ Thiago Cavalcante Simonato ${ }^{2}$ \\ Edson Paulo Domingues ${ }^{3}$
}

Resumo: Os princípios do desenvolvimento desigual são importantes para a compreensão da realidade regional brasileira, que apresenta contornos peculiares pela dependência em relação à exportação de commodities. Dada a rigidez locacional e a volatilidade dos preços característica desse mercado, a distribuição espacial dos impactos dessas atividades assume importância na persistência das desigualdades regionais. Este trabalho avança a partir do uso do modelo IMAGEM-B (Integrated Multi-Regional Applied General Equilibrium Model - Brazil), configurado para captar os impactos que o aumento da demanda externa por commodities teve sobre o desempenho econômico brasileiro, permitindo identificar os principais canais capazes de estimular o crescimento econômico. Resultados preliminares apontam que a economia brasileira apresentou respostas significativas ao efeito-preço das exportações (investimento, emprego regional, renda e consumo), ao efeito-quantum nas exportações para outras regiões exportadoras (exportação e importação domésticas) e ao resultado agregado do PIB. As tendências observadas refletem não apenas diferentes níveis de industrialização e de estruturas produtivas regionais, mas também uma concentração econômica (seletiva setorial e espacialmente) sustentada numa divisão regional da produção, que não tem permitido, aparentemente, reduzir as desigualdades regionais.

Palavras-Chave: Commodities, Desigualdades Regionais, Equilíbrio Geral Computável.

\begin{abstract}
The principles of uneven development are important for understanding the Brazilian regional reality, which has peculiar contours by dependence on commodity exports. Given the locational rigidity and the volatility of prices characteristic of this market, the spatial distribution of the impacts of these activities assumes importance in the persistence of regional inequalities. This work proceeds from the use of IMAGEM-B model (Integrated Multi-Regional Applied General Equilibrium Model - Brazil) configured to capture the impact that the increase in foreign demand for commodities had on Brazil's economic performance, allowing to identify the main channels capable of stimulating economic growth. Preliminary results indicate that the Brazilian economy showed significant responses to effect price of exports (investment, regional employment, income and consumption), the quantum effect in exports to other exporting regions (export and domestic import) and the aggregate result of GDP. The observed trends reflect not only different levels of industrialization and regional production structures, but also an economic concentration (sectoral and spatially selective) held a regional division of production, which has not allowed apparently reduce regional inequalities.
\end{abstract}

Keywords: Commodities, Regional Inequalities, Computable General Equilibrium.

JEL Classification: R11, R13, C68.

\footnotetext{
${ }^{1}$ Doutorando em Economia no CEDEPLAR/UFMG e professor do Departamento de Economia da UFES.

${ }^{2}$ Graduado em Economia pela UFRRJ e mestrando em Economia no CEDEPLAR/UFMG.

${ }^{3}$ Doutor em Economia pela FEA/USP e professor do CEDEPLAR/UFMG.
} 


\section{Introdução}

As disparidades regionais têm sido objeto de estudo em vários países, especialmente nos subdesenvolvidos, nos quais os diferenciais de renda e crescimento são mais acentuados (WILTGEN, 1991). Nas últimas décadas vários estudos trouxeram grandes contribuições para o debate em torno do desenvolvimento regional e uma das principais constatações foi a de que o processo de crescimento econômico acontece de forma desigual entre as regiões. Conforme observa Perroux (1955, p. 146), “o crescimento não aparece por toda a parte; manifesta-se em pontos ou pólos de crescimento, com intensidades variáveis, expande-se por diversos canais e tem efeitos terminais variáveis no conjunto da economia".

Em direção similar à de Perroux, Myrdal (1957) apresentou as razões pelas quais as economias regionais tenderiam a divergir ao longo do tempo. Com base no princípio da causalidade cumulativa, a argumentação era a de que as forças de mercado tenderiam a aumentar as desigualdades regionais, pois as atividades que apresentassem as maiores remunerações se concentrariam em determinadas regiões e, em função de crescentes economias internas e externas, esse processo se tornaria cumulativo. Ou seja, as desigualdades seriam reforçadas pelas forças de mercado e as regiões seguiriam caminhos divergentes, embora Myrdal reconhecesse a existência de efeitos de espraiamento desse processo (DINIZ, 2001). A ideia de polarização de Myrdal é de uma permanente concentração, pois os efeitos propulsores (ou de espraiamento) provocados nas demais regiões não seriam capazes de reverter esse processo de concentração, a não ser em algumas poucas regiões (WILTGEN, 1991).

Hirschman (1958) também analisou o processo de polarização e constatou que as regiões mais desenvolvidas atraíam capital e trabalho qualificado das regiões mais atrasadas, reforçando a desigualdade entre elas. Assim como Myrdal, ele também reconhecia a existência de alguns efeitos positivos das regiões desenvolvidas sobre as regiões atrasadas (DINIZ, 2011). Porém, opostamente a Myrdal, que interpretava a desigualdade como um problema, Hirschman considerava as disparidades como necessárias ao processo de crescimento, que seria alcançado por meio de uma série de desequilíbrios que estimulariam as regiões periféricas a potencializarem seus recursos escassos (MONASTERIO e CAVALCANTI, 2011).

North (1977) discutiu ideias relacionadas à desigualdade regional a partir do conceito de Base de Exportação, analisando principalmente a conexão entre o crescimento de uma região e o sucesso de suas exportações. A base de exportação de uma região dependeria essencialmente dos movimentos de mudança na demanda por seus produtos exportáveis, de modo que, embora North acreditasse numa convergência regional no longo prazo, as oscilações desses fatores dariam origem a uma tendência de desenvolvimento desigual em função de retornos crescentes de escala ou de economias de especialização regional.

Esses princípios do desenvolvimento desigual são importantes para a compreensão da realidade regional do Brasil, um país marcado historicamente por significativas diferenças econômicas em seu espaço geográfico. As atividades econômicas no país foram desenvolvidas conforme as necessidades de cada região em se inserir no mercado internacional, dando origem a economias regionais voltadas para fora e com pouca integração nacional (DINIZ, 2001). Esse isolamento relativo das regiões evidenciou a quase inexistência do mercado interno no Brasil até a metade do século $\mathrm{XX}$, período no qual as diferentes trajetórias seguidas pelas regiões foram determinadas por vários ciclos de exportação.

Os aspectos mais significativos da evolução recente das desigualdades regionais no Brasil requerem a breve compreensão de três momentos: a concentração econômica (até os anos 1970), a desconcentração (1975 a 1985) e seu esgotamento (pós anos 1990).

As grandes transformações que ocorreram no Brasil desde a década de 1950, especialmente no que se refere aos processos de industrialização e de urbanização, romperam com o modelo de desenvolvimento anterior e evidenciaram uma trajetória marcada por uma dinâmica de natureza centrípeta, centralizando os recursos nos centros econômicos mais dinâmicos, notadamente os localizados no centro-sul do país (CARLEIAL, 2011). Nessa fase de concentração, que durou até meados dos anos 1970 e que foi marcada pela formação do mercado interno nacional, as desigualdades regionais se ampliaram, uma vez que a base produtiva industrial mais eficiente da região Sudeste, e mais especificamente de São Paulo, induziu um processo de ajustamento das 
demais regiões ao avançar sobre os mercados anteriormente isolados (GUIMARÃES NETO, 1997). Autores como Furtado (1976) e Cano (1977) retratam detalhadamente esses fatos em suas obras.

Posteriormente, entre 1975 e 1985, houve um breve período de desconcentração (ou integração produtiva) que consolidou o surgimento de especializações regionais fora do Sudeste. A diminuição do peso da indústria de transformação na matriz industrial brasileira, resultado da inserção comercial do país como grande produtor de bens baseados em recursos naturais, ampliou a desconcentração produtiva regional, uma vez que novas áreas da fronteira agropecuária foram incorporadas, especialmente nas regiões Norte e Centro-Oeste, e regiões periféricas com grandes reservas minerais foram acionadas (MACEDO e MORAIS, 2011). Muitos projetos significativos (hidrelétricas, não ferrosos, químicos e petroquímicos) foram instalados nessas regiões, acelerando seu crescimento (CANO, 1997). Além disso, os investimentos em infraestrutura ampliaram as ligações entre as regiões e auxiliaram o processo de convergência regional. Mas Diniz e Crocco (1996) observam que esse processo de desconcentração também deu origem a uma expressiva aglomeração em várias cidades grandes e médias (inclusive capitais) das regiões Sudeste e Sul, o que foi denominado por Diniz (1993) de reaglomeração poligonal. Cabe observar que, apesar da tendência no período ter sido descentralizadora, as explorações não foram, em geral, industrializantes, pois as novas áreas de exploração mineral tenderam à especialização para exportação, configurando-se em enclaves ${ }^{4}$. Assim, o processo de desconcentração pode ser considerado seletivo, setorial e espacialmente, e insuficiente para reverter o alto grau de desigualdade e heterogeneidade existente na economia brasileira.

O terceiro momento a ser destacado, que se iniciou a partir de 1985, foi marcado pelo agravamento da crise econômica do país e, ao mesmo tempo, pela crise financeira do Estado, o que provocou a deterioração dos principais instrumentos de política econômica, notadamente do investimento público em infraestrutura, do setor produtivo estatal e dos incentivos fiscais. Em razão disso, houve um relativo equilíbrio na participação das economias regionais no produto, indicando o esgotamento do processo de desconcentração (GUIMARÃES NETO, 1997). Na visão de Diniz (1995), o processo de abertura econômica favoreceu a reconcentração da produção industrial nas áreas mais industrializadas do país ${ }^{5}$, em função das melhores condições de competição no mercado internacional, e, ao mesmo tempo, mas em menor escala, contribuiu para a desconcentração no sentido das regiões Centro-Oeste e Norte a partir da expansão das exportações de grãos e de bens minerais. Na mesma direção, Pacheco (1999) constatou relativa continuidade do processo de desconcentração acompanhado pelo aumento da heterogeneidade interna das regiões brasileiras, com o surgimento de "ilhas de produtividade" em quase todas as regiões. De forma geral, as várias interpretações sobre esse período confirmam uma tendência de interrupção da desconcentração espacial do crescimento que estava em curso.

A atual dinâmica regional brasileira, consolidada ao longo desses três períodos, apresenta contornos mais peculiares pelo fato de haver uma significativa dependência da economia em relação à exportação de commodities e a produção desses bens, por sua vez, está distribuída de forma desigual no território. Em função da rigidez locacional e da volatilidade dos preços característica do mercado de commodities (baixa elasticidade-preço da oferta), a distribuição espacial dos impactos dessas atividades assume grande importância no entendimento da persistência das desigualdades regionais ao longo do tempo.

Os preços internacionais ${ }^{6}$ das commodities apresentaram grande evolução desde o ano 2005 e, mesmo com a crise de 2008, esses preços ainda permanecem em níveis bem maiores aos registrados até então. A relevância desse aumento de preços reside no forte estímulo que as regiões produtoras têm para intensificar a exportação desses bens. A resposta aos altos preços internacionais pode ser vista a partir da participação das commodities na pauta de exportação brasileira, que saltou de $57,96 \%$ em 2005 para $71,24 \%$ em 2014.

\footnotetext{
${ }^{4}$ Uma das exceções foi a indústria de Minas Gerais que, beneficiando-se da base de recursos naturais, expandiu-se principalmente em razão da intensificação da integração com a indústria paulista (MELO, 2000).

5 Azzonni (1997), ao analisar o mesmo período, observou uma recuperação expressiva de São Paulo e uma tendência de crescimento de Minas Gerais, enquanto as regiões Sul e Nordeste perderam participação.

${ }^{6}$ Apesar da escalada de preço das commoditites ter se iniciado por volta de 2002, a análise dos dados neste artigo é feita a partir do ano de 2005 em razão da base de dados utilizada no modelo de Equilíbrio Geral Computável.
} 
Os efeitos econômicos da exportação de commodities na economia brasileira envolvem importantes aspectos micro e macroeconômicos. Ao se considerar a heterogeneidade espacial do desenvolvimento brasileiro, a expansão e a retração da exportação de commodities altera a estrutura geral de preços relativos da economia, impondo modificações ao cenário regional. Esse padrão de inserção internacional tende a estimular setores distintos, com estruturas e multiplicadores próprios.

Gráfico 01 - Receita, Quantidade e Preço Médio das Exportações de Commodities (2005 a 2014)

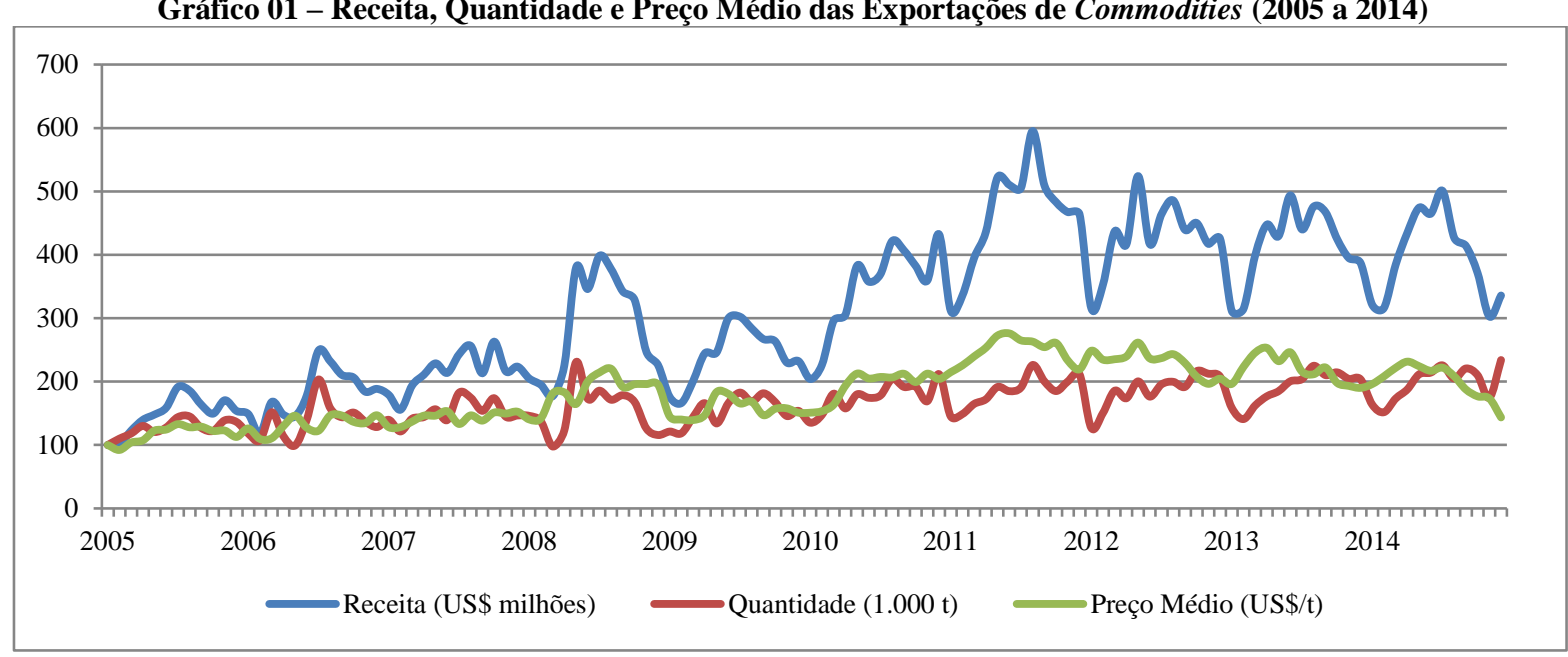

Fonte: SECEX/MDIC. Elaboração própria.

Descrição: Índice Base $(2005=100)$

Considerando as relações entre os setores e as diferentes regiões, este trabalho pretende avançar, a partir de um modelo de Equilíbrio Geral Computável (EGC), no entendimento sobre os impactos que o aumento e a diminuição da demanda externa por commodities tiveram sobre o desempenho econômico brasileiro e, também, sobre os efeitos alocativos inter-regionais como resultados de forças de mercado, permitindo identificar os principais canais capazes de estimular o crescimento econômico e seu impacto na concentração regional. $O$ que se pretende discutir, portanto, é se o recente ciclo de preços das commodities ${ }^{7}$ reforçou ou atenuou os padrões de crescimento regional desigual no Brasil.

\section{Metodologia}

Apesar da complexidade de se analisar essa questão, especialmente com relação à quantidade de variáveis envolvidas e suas inter-relações, a teoria econômica dispõe de instrumentos analíticos efetivos para isso, destacando-se, em especial, os modelos de Equilíbrio Geral Computável (EGC). Os modelos de EGC, assim como todos os modelos que objetivam representar uma economia real complexa, são representações simplificadas do sistema econômico, mas que consideram os mecanismos mais importantes da economia, ultrapassando aquilo que pode ser alcançado pelo senso comum ou por modelos mais simples como os de equilíbrio parcial (DOMINGUES, 2002). As economias regionais, dadas suas especificidades, não podem ser consideradas versões em menor escala das economias nacionais, inclusive porque os efeitos de transbordamento do crescimento e de polarização são mais intensos nas relações inter-regionais devido às interações mais intensas que existem entre as regiões (HADDAD, 2003). Embora sempre exista alguma incerteza em relação aos valores de parâmetros ${ }^{8}$ desses modelos, sua utilização permite constatar as direções e as magnitudes relativas de alterações no cenário econômico, possibilitando identificar relações existentes entre setores e agentes econômicos que dificilmente

\footnotetext{
${ }^{7}$ A cesta de commodities segue a classificação da Secretaria de Comércio Exterior do Ministério do Desenvolvimento, Indústria e Comércio Exterior (SECEX/MDIC). Os 23 produtos são: açúcar em bruto; açúcar refinado; algodão; café em grão; carne bovina "in natura"; carne de frango "in natura"; carne suína "in natura"; celulose; couro; farelo de soja; fumo em folhas; milho; óleo de soja em bruto; soja em grão; suco de laranja; etanol; gasolina; óleos combustíveis; petróleo em bruto; alumínio; laminados planos; minério de ferro; semimanufaturados de ferro/aço.

${ }^{8}$ Nesses modelos, os parâmetros são, em geral, calibrados, e não estimados a partir de técnicas estatísticas como nos modelos econométricos. Assim, os valores desses parâmetros são calculados a partir de uma observação das variáveis exógenas em um determinado ano base, servindo de referência para as simulações (FERREIRA FILHO, 2011).
} 
seriam observadas a partir de outros métodos (GURGEL, 2012). De qualquer forma, sempre há problemas derivados do conflito entre a simplificação teórica e a realidade empírica.

Os modelos de EGC são elaborados a partir de bases de dados consistentes, coerentes com a teoria econômica, compreendendo a economia como um sistema inter-relacionado em que o equilíbrio de todas as variáveis é determinado simultaneamente, permitindo que qualquer perturbação no sistema possa ser dimensionada. Esse é o caso do aumento das exportações de commodities, que apresenta um alcance amplo em termos geográficos e econômicos, com efeitos significativos na alocação de recursos. Em função dessas características, pode-se dizer que um modelo de equilíbrio geral computável (EGC) é um instrumento adequado para a análise, de forma completa, do problema proposto.

\subsection{Modelo IMAGEM-B}

O presente trabalho faz uso do modelo IMAGEM-B (Integrated Multi-Regional Applied General Equilibrium Model - Brazil), que leva em consideração as características estruturais e interregionais do sistema econômico brasileiro de forma integrada e consistente, especialmente configurado para captar os impactos dos choques nas commodities selecionadas.

Trata-se de um modelo multi-regional estático (variações anuais em relação a uma trajetória tendencial a partir de um período base) do tipo Johansen ${ }^{9}$, com estrutura bottom-up para os 27 estados, que segue a base teórica do modelo TERM (HORRIDGE et al, 2005), e top-down para as 558 microrregiões brasileiras ${ }^{10}$. Ao nível estadual, as regiões são endógenas e o comportamento dos agentes é modelado. Ao nível nacional, os resultados são gerados através de agregações dos resultados estaduais e, ao nível microrregional, os resultados são decomposições consistentes do resultado estadual de forma a manter coerência com a estrutura agregada em quatro setores do PIB municipal do IBGE em cada estado.

Os dados utilizados na calibragem do módulo top-down microrregional são as participações de cada microrregião nos setores do modelo. Os dados utilizados são o PIB municipal/setorial do IBGE (quatro grandes setores), os dados setoriais/municipais de emprego da RAIS e o mapeamento de estados, microrregiões e municípios do IBGE. Além disso, o modelo considera 27 estados, 110 produtos/setores e 4 demandantes (famílias, investimento, exportação e governo). Na base de dados do modelo os 23 produtos que terão choques (commodities) e os dois bens de margens (Comercio, TranspCarga) são mantidos e os outros produtos/setores são agregados em Resto da Agropecuária, Resto da Indústria e Serviços. O ano-base do banco de dados é 2005.

As principais características da estrutura teórica do modelo estão relacionadas com a tecnologia de produção setorial, a demanda das famílias, a demanda por investimentos e a demanda por exportações. Dado o foco regional desta análise, o arranjo do sistema de composição da demanda tem destacada relevância. Essa estrutura é traçada na figura 01.

\footnotetext{
${ }^{9}$ Como discutido em Dixon et al. (1982), nos modelos estáticos a preocupação não é com a trajetória do investimento ao longo do tempo e sim com a alocação dos investimentos em certas atividades e regiões. Os modelos da tradição de Johansen têm o seu método de solução dado de forma linear e os resultados são apresentados através de taxas de crescimento (GUILHOTO, 2011). ${ }^{10}$ A decomposição top-down segue o modelo de Leontief et al. (1965) e implementado em Dixon et al. (1982) no modelo Orani.
} 
Figura 01 - Mecanismo de Composição da Demanda no Modelo IMAGEM-B

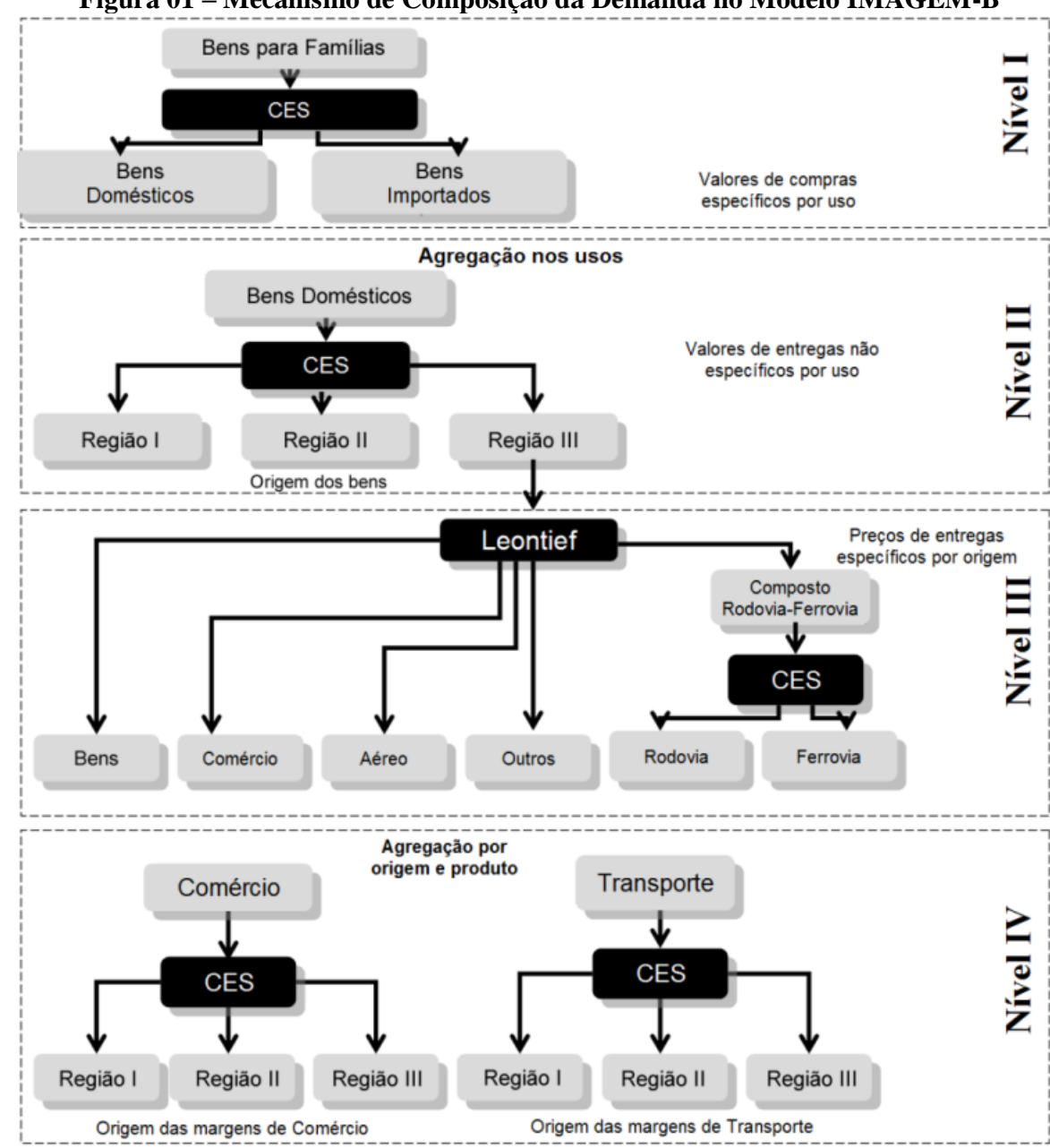

Fonte: adaptado de MAGALHÃES (2009)

Em relação à tecnologia de produção setorial, cada setor pode produzir mais de um produto utilizando insumos domésticos e importados, opção que é tratada a partir da hipótese de separabilidade para reduzir a necessidade de parâmetros. Além disso, o fator terra é fixo e a tecnologia de produção apresenta retornos constantes de escala ${ }^{11}$. O tratamento da demanda das famílias, que consomem bens domésticos e importados em cada região em proporções fixas, é baseado em um problema de maximização de utilidade, cuja solução segue etapas hierarquizadas. A demanda por investimentos ocorre a partir das escolhas dos insumos (domésticos e importados) utilizados na criação de capital por meio de um processo de minimização de custos sujeito a uma estrutura de tecnologia hierarquizada. Além disso, a concepção temporal de investimento empregada não tem correspondência com um calendário exato, pois a ideia é captar os efeitos de choques na alocação do investimento entre as regiões, ou seja, trata-se de uma análise de steady-state rumo a um novo equilíbrio. Por fim, a demanda por exportações, em um modelo no qual o setor externo é exógeno, parte da hipótese de curvas de demanda negativamente inclinadas nos próprios preços no mercado mundial. Assim, um vetor de elasticidades (diferenciado por produto, mas não por região de origem) representa a resposta da demanda externa a alterações no preço FOB das exportações (MAGALHÃES, 2009).

No nível I, as famílias escolhem entre bens domésticos e importados seguindo uma função do tipo CES (Constant Elasticity of Substitution), que parte da hipótese de Armington na diferenciação dos produtos, em que bens de diferentes origens são tratados como substitutos imperfeitos (PEROBELLI, 2004). A elasticidade de substituição entre o composto doméstico e

\footnotetext{
${ }^{11}$ A utilização de retornos crescentes de escala em modelos EGC regionais não é uma hipótese usual, pois a introdução dessa hipótese pode causar problemas teóricos (existência ou multiplicidade de equilíbrios) e empíricos (ausência de estimativas econométricas). Em razão disso, pode-se considerar que os resultados obtidos correspondam ao limite inferior dos impactos observados (MAGALHÃES, 2009). Uma abordagem paramétrica de retornos crescentes de escala em modelos EGC pode ser vista em Haddad (2004) e Haddad e Hewings (2005).
} 
importado $\left(\sigma_{x}\right)$ é específica por bem, mas comum por uso e região de uso. O nível II, por sua vez, especifica o sistema de origem do componente doméstico entre as regiões também a partir de uma função CES $\left(\sigma_{d}\right)$, o que implica que regiões com diminuição do custo relativo de produção aumentam seu market share na região de destino do produto. O nível III indica a estrutura de valores básicos e margens de comércio e transporte dos bens entre as regiões. Considera-se que a parcela de cada componente no preço final é fixa e, sendo assim, segue uma função Leontief. No nível IV são definidas as origens das margens de transporte entre as várias regiões do modelo. Essas margens são distribuídas de forma equitativa entre origem e destino, havendo algum grau de substituição nos fornecedores de margem, regulada pela elasticidade $\left(\sigma_{t}\right)$. Para as margens de comércio tem-se que a maior parte da margem é produzida na região de destino (uso), com uma elasticidade calibrada próximo de zero (MAGALHÃES, 2009).

\subsection{Simulação}

Para o objetivo deste trabalho, foi utilizado um fechamento de curto prazo, que se diferencia principalmente por considerar o estoque de capital fixo, como segue:

1) Mercado de Fatores: oferta de capital e de terra fixa (nacionalmente, regionalmente e entre setores) para todos os setores;

2) Mercado de Fatores: emprego regional endógeno (responde a variações no salário real regional) e emprego nacional fixo;

3) Salário real regional endógeno (salário nominal indexado ao IPC).

4) Consumo real ajusta-se endogenamente e segue a renda disponível.

5) Saldo comercial externo, como proporção do PIB, é endógeno.

6) Gasto real do governo exógeno.

Cabe observar que o fechamento representa hipóteses de operacionalização do modelo, associadas ao horizonte temporal hipotético das simulações, que se relaciona ao tempo necessário para que a alteração das variáveis endógenas se equilibre novamente.

A partir da estrutura do modelo IMAGEM-B, a simulação realizada utiliza as taxas de crescimento anual das commodities (preços e quantidades), conforme a tabela 01.

A simulação de cenários de expansão da produção e exportação das commodities (deslocamentos na curva de demanda por exportações) busca identificar quais os mecanismos de transmissão desse choque na estrutura de interação entre as regiões e verificar qual o impacto do aumento das interações com o setor externo para a estrutura econômica das regiões.

Tabela 01 - Taxas de Crescimento Anual das Commodities (Preços e Quantidades)

\begin{tabular}{c|l|r|r|r|r}
\hline \multirow{2}{*}{\multicolumn{2}{c|}{ Classificação }} & \multicolumn{2}{c|}{ Quantidade (1.000 t) } & \multicolumn{2}{c}{ Preço (US\$/t) } \\
\cline { 2 - 5 } & $\mathbf{2 0 0 5 - 2 0 1 1}$ & $\mathbf{2 0 1 1 - 2 0 1 4}$ & $\mathbf{2 0 0 5 - 2 0 1 1}$ & $\mathbf{2 0 1 1 - 2 0 1 4}$ \\
\hline 2 & MilhoGrao & 43,337 & 21,464 & 17,099 & $-9,903$ \\
\hline 5 & SojaGrao & 4,070 & 8,487 & 13,023 & 0,722 \\
\hline 8 & FumoFolha & $-2,379$ & $-3,612$ & 12,274 & $-0,717$ \\
\hline 9 & AlgodaoHerba & 11,674 & $-0,321$ & 10,524 & $-3,584$ \\
\hline 11 & CafeGrao & 4,800 & 2,622 & 15,708 & $-9,162$ \\
\hline 19 & PetroleoGas & 13,903 & $-3,543$ & 15,511 & $-3,293$ \\
\hline 20 & MinerioFerro & 6,702 & 1,009 & 25,371 & $-12,242$ \\
\hline 22 & MinMetNaoFer & $-2,354$ & $-10,670$ & 4,718 & $-3,746$ \\
\hline 24 & AbatePrCarne & $-4,564$ & 10,618 & 14,733 & $-1,846$ \\
\hline 25 & CarneSuino & $-4,624$ & $-1,028$ & 7,246 & 4,045 \\
\hline 26 & CarneAves & 4,407 & 0,547 & 8,705 & $-1,149$ \\
\hline 29 & OleoSojaBrut & $-5,949$ & $-6,322$ & 17,454 & $-8,584$ \\
\hline 38 & PrUsinasAcuc & 5,734 & $-1,125$ & 18,209 & $-9,360$ \\
\hline 41 & OutProdAlime & 11,238 & $-0,990$ & 7,869 & $-3,672$ \\
\hline 48 & CouroArtefat & 0,749 & 8,521 & 5,727 & 0,853 \\
\hline 51 & CelulosPapel & 8,213 & 5,486 & 7,355 & $-3,849$ \\
\hline 55 & GasolAutomot & $-30,409$ & 2,983 & 10,256 & $-0,012$ \\
\hline 57 & OleoCombust & $-0,500$ & $-0,664$ & 16,292 & $-1,714$ \\
\hline 60 & Alcool* & 9,553 & $-8,213$ & 15,311 & $-4,034$ \\
\hline 74 & SemiAcabAco & $-3,201$ & 6,235 & $-5,879$ \\
\hline
\end{tabular}

Fonte: SECEX/MDIC. Elaboração própria.

* Quantidade em milhões de litros e preço em US\$/1 
O primeiro choque (2005-2011) foi aplicado ao cenário-base do modelo (2005), gerando um conjunto de resultados em termos de taxas de crescimento anual para o período. Posteriormente, a partir do primeiro choque, a base de dados do modelo foi atualizada para o ano de 2011, constituindo um novo cenário econômico. Neste novo cenário foi aplicado o segundo choque (20112014). Os resultados obtidos apresentam as variações anuais em relação a uma trajetória tendencial (baseline), representando apenas os efeitos adicionais decorrentes dos choques das commodities, não sendo consideradas outras mudanças.

Como o IMAGEM-B utiliza equações linearizadas, há métodos numéricos multistep de correção de erros de linearização que consistem no particionamento dos choques e no recálculo do novo equilíbrio a partir de variações menores. Neste trabalho, a partir do software GEMPACK, foi utilizado o método Gragg com interpolação de resultados de 2, 4 e 6 passos.

\section{Resultados}

A evolução conjunta da estrutura regional e do ciclo econômico de expansão das exportações de commodities depende da existência de mecanismos de transmissão por meio dos quais as disparidades regionais podem ser condicionadas ao longo do tempo. Os resultados das simulações fornecem uma ideia da magnitude do choque na economia, permitindo identificar os diferentes impactos em cada região e, portanto, compreender o grau de dependência do crescimento da economia ao comportamento dos preços das commodities.

\subsection{Efeito-Preço}

Os primeiros resultados apresentados se referem ao efeito-preço das exportações de commodities sobre o investimento, o emprego regional, a renda e o consumo (tabela 02).

O primeiro componente do efeito-preço afeta a alocação dos investimentos em certas atividades e regiões. No primeiro período (2005-2011), como há crescimento significativo das exportações de commoditites, todos os estados apresentam variação anual positiva do investimento. $\mathrm{O}$ vínculo entre a estrutura produtiva e as flutuações do investimento pode ser visualizado mais claramente no caso de regiões cujas exportações dependem de poucas matérias-primas. É o caso de estados como o Pará, Rio Grande do Norte, Alagoas, Sergipe, Minas Gerais, Espírito Santo e Mato Grosso.

As variações no investimento apresentam uma reversão, do primeiro para o segundo período, de forma que, em geral, os estados que apresentam significativo crescimento do investimento também registram as maiores reduções. Este resultado evidencia o grau de especialização produtiva destas regiões na produção de commodities. É importante observar, novamente, que os resultados apresentados indicam apenas a variação do investimento advinda dos choques das exportações de commodities em relação ao cenário de 2005 e de 2011.

Além disso, cabe observar que para quase todos os estados (exceto Amapá), o crescimento anual do investimento no primeiro período é bem superior à redução observada no segundo. Mesmo considerando que a base de comparação do segundo período é maior, essa diferença nas variações do investimento indica que o movimento provocado pelas commodities não foi totalmente revertido. Estas informações podem ser observadas também no mapa 01.

A volatilidade de preços típica dos ciclos de commodities tem implicações importantes sobre as regiões com elevado grau de dependência desses produtos ao reduzir as taxas de investimento e do crescimento em longo prazo. Isso porque, embora a contração do investimento tenha efeitos de curto prazo sobre a demanda agregada e sobre o emprego, implica em menor crescimento do estoque de capital, o que prejudica a capacidade da economia de gerar empregos. Além disso, essa contração tem um efeito negativo sobre a produtividade ao postergar a adoção de métodos de produção baseados em um uso mais intensivo de capital e de tecnologia. Em relação aos aspectos do desenvolvimento regional, um problema associado às atividades de commodities é o fato de que muitas empresas costumam operar em enclaves e o alto grau de concentração da propriedade faz com que o aumento da produtividade se concentre em poucas empresas e sua disseminação para outros setores seja bastante reduzida (CEPAL, 2014).

Além disso, a volatilidade de preços altera a rentabilidade relativa dos investimentos entre os setores ou regiões, redefinido constantemente a orientação espacial desses investimentos. No caso 
dos estados com elevada dependência em relação aos setores exportadores de commodities, pode-se ter ideia do impacto que a alta de preços teve na tendência de se concentrar os investimentos justamente nos setores já estabelecidos, reforçando o padrão de especialização dessas economias e, com isso, dificultando a transformação da estrutura produtiva (CEPAL, 2014). Esse processo tende a ser cumulativo, estimulando a concentração em certas regiões e ampliando as desigualdades via crescentes economias internas e externas, nos moldes das ideias apresentadas por Myrdal (1957).

Tabela 02 - Efeito-Preco: Investimento, Emprego, Salário Real e Consumo (2005-2011 e 2011-2014)

\begin{tabular}{|c|c|c|c|c|c|c|c|c|c|}
\hline \multirow{2}{*}{ Região } & \multirow{2}{*}{ Estados } & \multicolumn{2}{|c|}{ Investimento } & \multicolumn{2}{|c|}{ Emprego } & \multicolumn{2}{|c|}{ Salário Real } & \multicolumn{2}{|c|}{ Consumo } \\
\hline & & $05-11$ & $11-14$ & $05-11$ & 11-14 & $05-11$ & 11-14 & $05-11$ & 11-14 \\
\hline \multirow{7}{*}{ Norte } & Rondônia & 0,250 & $-0,150$ & $-0,340$ & 0,120 & 0,860 & $-0,230$ & $-0,150$ & 0,060 \\
\hline & Acre & 0,110 & $-0,020$ & $-0,410$ & 0,150 & 0,760 & $-0,190$ & $-0,310$ & 0,130 \\
\hline & Amazonas & 1,100 & $-0,410$ & $-0,120$ & 0,020 & 1,160 & $-0,380$ & 0,370 & $-0,200$ \\
\hline & Roraima & 0,440 & $-0,150$ & $-0,210$ & 0,090 & 1,040 & $-0,280$ & 0,160 & $-0,020$ \\
\hline & Pará & 2,180 & $-1,290$ & 0,000 & $-0,110$ & 1,330 & $-0,550$ & 0,650 & $-0,490$ \\
\hline & Amapá & 0,490 & $-1,380$ & $-0,320$ & 0,000 & 0,890 & $-0,390$ & $-0,100$ & $-0,230$ \\
\hline & Tocantins & 0,690 & $-0,120$ & $-0,070$ & 0,100 & 1,230 & $-0,250$ & 0,490 & 0,010 \\
\hline \multirow{9}{*}{ Nordeste } & Maranhão & 0,560 & $-0,110$ & $-0,150$ & 0,130 & 1,130 & $-0,220$ & 0,310 & 0,070 \\
\hline & Piauí & 0,600 & $-0,260$ & $-0,170$ & 0,030 & 1,100 & $-0,360$ & 0,250 & $-0,160$ \\
\hline & Ceará & 0,590 & $-0,210$ & $-0,220$ & 0,060 & 1,020 & $-0,320$ & 0,130 & $-0,100$ \\
\hline & Rio Grande do Norte & 5,350 & $-1,610$ & 0,770 & $-0,270$ & 2,400 & $-0,770$ & 2,510 & $-0,870$ \\
\hline & Paraíba & 1,410 & $-0,690$ & $-0,040$ & $-0,060$ & 1,270 & $-0,480$ & 0,560 & $-0,370$ \\
\hline & Pernambuco & 1,160 & $-0,590$ & $-0,080$ & $-0,050$ & 1,220 & $-0,470$ & 0,470 & $-0,360$ \\
\hline & Alagoas & 3,240 & $-1,990$ & 0,310 & $-0,300$ & 1,770 & $-0,810$ & 1,410 & $-0,940$ \\
\hline & Sergipe & 3,770 & $-1,380$ & 0,690 & $-0,270$ & 2,300 & $-0,770$ & 2,330 & $-0,880$ \\
\hline & Bahia & 1,290 & $-0,450$ & 0,150 & 0,010 & 1,540 & $-0,380$ & 1,010 & $-0,200$ \\
\hline \multirow{4}{*}{ Sudeste } & Minas Gerais & 3,340 & $-1,670$ & 0,240 & $-0,170$ & 1,670 & $-0,630$ & 1,250 & $-0,640$ \\
\hline & Espírito Santo & 9,970 & $-4,460$ & 0,970 & $-0,580$ & 2,680 & $-1,190$ & 2,980 & $-1,600$ \\
\hline & Rio de Janeiro & 2,040 & $-0,820$ & 0,080 & $-0,090$ & 1,440 & $-0,520$ & 0,850 & $-0,450$ \\
\hline & São Paulo & 0,920 & $-0,280$ & $-0,060$ & 0,030 & 1,250 & $-0,360$ & 0,510 & $-0,160$ \\
\hline \multirow{3}{*}{ Sul } & Paraná & 0,900 & $-0,250$ & $-0,050$ & 0,070 & 1,260 & $-0,300$ & 0,530 & $-0,060$ \\
\hline & Santa Catarina & 0,510 & $-0,270$ & $-0,250$ & 0,100 & 0,990 & $-0,270$ & 0,070 & 0,000 \\
\hline & Rio Grande do Sul & 0,510 & $-0,090$ & $-0,260$ & 0,120 & 0,970 & $-0,230$ & 0,040 & 0,060 \\
\hline \multirow{4}{*}{ Centro-Oeste } & Mato Grosso do Sul & 1,830 & $-0,090$ & 0,240 & 0,110 & 1,670 & $-0,240$ & 1,240 & 0,030 \\
\hline & Mato Grosso & 2,470 & $-0,100$ & 0,810 & 0,310 & 2,470 & 0,020 & 2,620 & 0,500 \\
\hline & Goiás & 1,100 & $-0,330$ & 0,060 & 0,100 & 1,410 & $-0,260$ & 0,790 & 0,000 \\
\hline & Distrito Federal & 0,440 & $-0,130$ & $-0,350$ & 0,110 & 0,850 & $-0,250$ & $-0,160$ & 0,020 \\
\hline BRASIL & & 1,320 & $-0,500$ & 0,000 & 0,000 & 1,330 & $-0,400$ & 0,710 & $-0,240$ \\
\hline
\end{tabular}

Fonte: Elaboração própria.

No caso brasileiro, em que há vários estados com elevada dependência em relação aos setores exportadores de commodities, é possível ressaltar o papel significativo dos setores de petróleo e gás e de mineração, que possuem grande peso nas exportações. Embora na última década tenha sido observado um aumento nos custos de investimento, de operação e de manutenção no setor de petróleo e gás natural, as altas dos preços internacionais mais do que compensaram esses custos, garantindo rentabilidades inéditas para a indústria e, por isso, estimulando a expansão da produção de acordo com o ritmo de crescimento da demanda global (CEPAL, 2013). As reservas comprovadas $^{12}$ de petróleo aumentaram, assim como as de gás natural. A produção de petróleo e de gás natural se mostra concentrada, uma vez que mais de $90 \%$ do petróleo e mais de $62 \%$ do gás natural estão no sudeste do país (ANP, 2014). Em consequência da concentração das atividades de exploração e produção de petróleo (upstream) na região Sudeste, as atividades de refino, transporte e distribuição (downstream) também se concentram nesta região como forma de ampliar as economias de escala na produção e reduzir as deseconomias de escala na distribuição.

Assim como ocorreu no setor de petróleo e gás natural, a elevação dos preços internacionais dos metais gerou maiores expectativas quanto aos rendimentos da mineração e, portanto, à redução do payback estimado, estimulando os investimentos nas atividades de exploração no setor. Em termos regionais, mais de $50 \%$ do setor de mineração do país se concentram na região Sudeste,

\footnotetext{
${ }^{12}$ Cabe observar que para que um recurso seja catalogado como reserva comprovada é preciso que a exploração ao longo da vida útil do reservatório seja considerada rentável. Neste caso, é possível compreender o efeito propulsor que a recente evolução dos preços internacionais teve sobre as atividades de prospecção e exploração.
} 
notadamente em Minas Gerais. A região Norte também apresenta participação significativa, embora seja equivalente à metade da participação da região Sudeste. Essa distribuição irregular é reforçada pelo fato de que o processamento dos minerais é, em geral, realizado próximo das jazidas, concentrando os impactos econômicos.

O segundo componente pelo qual o crescimento dos preços das commodities é capaz de atingir o crescimento econômico é através do aumento do emprego. Os impactos positivos sobre o emprego, no primeiro período, são associados à expansão das exportações e ao o estímulo para se aumentar os investimentos nas regiões exportadoras (em comparação ao custo de oportunidade de se aplicar recursos no setor industrial). E a perda de empregos, no segundo período, está relacionada à elevação das importações (mais concorrência no mercado doméstico). Em relação ao emprego, os resultados também podem ser vistos no mapa 02 .

No caso do emprego, é importante observar que as simulações foram realizadas a partir de um fechamento que considera o emprego regional endógeno (respondendo a variações no salário real regional) e emprego nacional fixo. Com isso, as regiões que ampliam a participação no emprego total o fazem em razão, necessariamente, da redução da participação de outras regiões, ou seja, o comportamento dos empregos resulta em soma zero. As variações regionais do emprego ocorrem pelos diferenciais de salário real. É importante observar que o modelo de EGC permite captar os efeitos indiretos do mercado de trabalho em outros setores e na atividade econômica em geral, e não só no setor de commodities.

No primeiro ciclo, o nível de empregos em quase todos os estados diminui em direção a alguns poucos estados, notadamente das regiões Sudeste e Centro-Oeste, ampliando algumas disparidades regionais, inclusive porque esses efeitos migratórios em direção às regiões mais dinâmicas tendem a ser seletivos, ao menos pelo fator idade e de renda. Esse resultado reforça a tese defendida por Hirschman (1958) de que as regiões mais desenvolvidas atraem trabalho qualificado das regiões mais atrasadas, reforçando a desigualdade entre elas. No segundo ciclo, essa tendência se reverte, mas em menor intensidade. A especialização produtiva tende a gerar menor oferta de trabalho, razão pela qual os estados com maior dependência dos setores exportadores apresentam as maiores reduções no emprego (Espírito Santo, Minas Gerais, Pará e alguns estados do Nordeste).

Em relação à renda (salário real), o impacto pode ser visto também no mapa 03. As regiões em expansão requerem mais trabalho, o que aumenta a remuneração do trabalho e desloca recursos produtivos das outras regiões da economia para as áreas em expansão. Seguindo a mesma tendência do investimento, os estados com maior taxa de crescimento anual do investimento via commodities também apresentaram a maior taxa de aumento do salario real. Apesar dos salários reais crescerem em todo o Brasil, reflexo do aumento de atividade, isso ocorre especialmente no caso dos estados de Mato Grosso, Espírito Santo, Minas Gerais, Sergipe e Rio Grande do Norte.

Em relação ao segundo período, a retração da atividade econômica pressiona os salários para baixo. Destaque para os estados do Espírito Santo, Minas Gerais, Rio de Janeiro, Bahia e Pará. O único estado que apresenta pouca variação dos salários reais é Mato Grosso, provavelmente pela existência de um modelo produtivo exportador agrícola que favorece a produção extensiva que não fomenta a criação de empregos, causando menos pressão nos salários. 

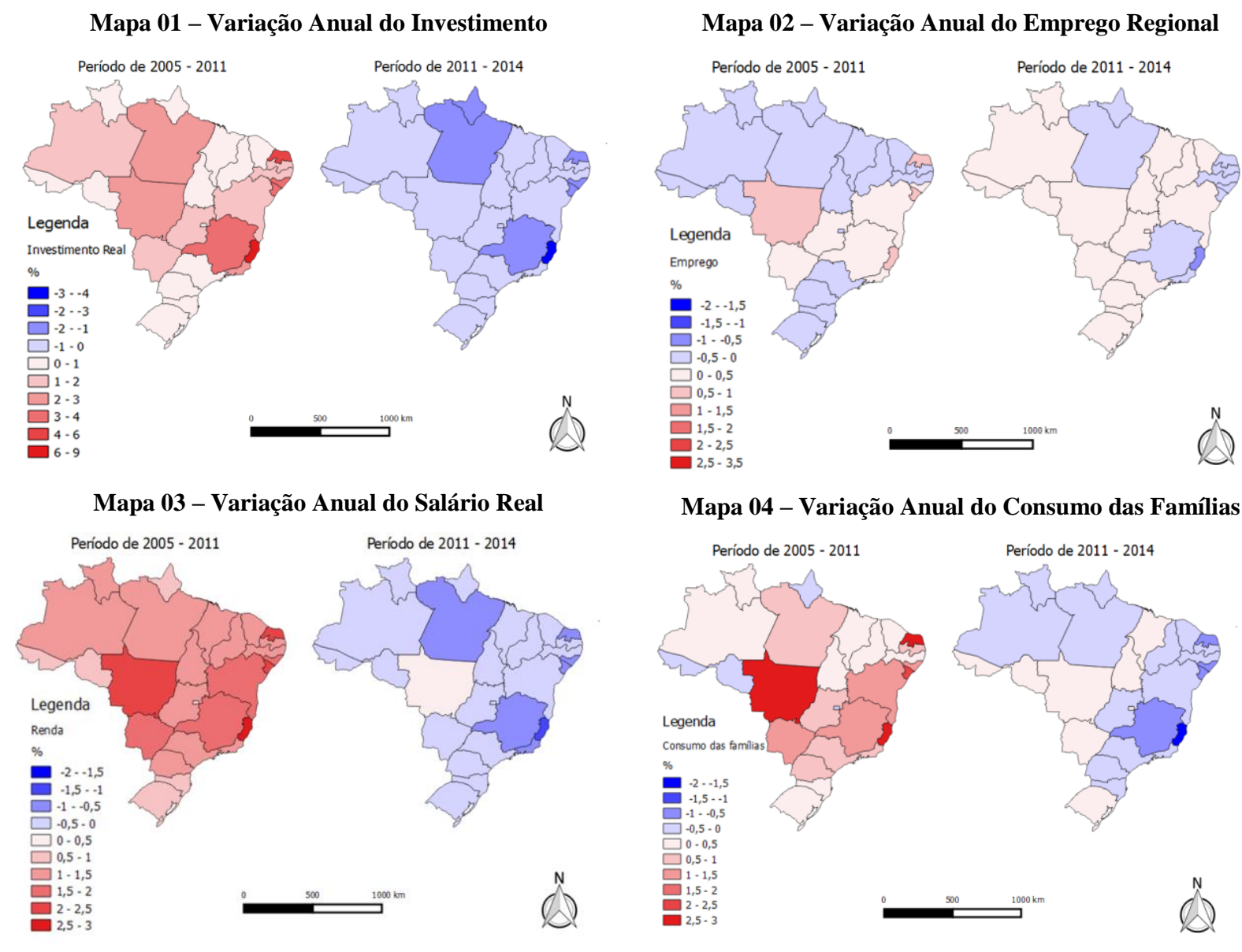

Fonte: Elaboração própria.

Os efeitos das variações das commodities sobre o consumo podem ser vistos no mapa 04. É importante observar que o consumo das famílias é, em muitos casos, considerado uma proxy para o bem-estar. De forma geral, o comportamento desta variável é semelhante ao da renda (salário real).

Um efeito associado ao ciclo de commoditites é a melhora do balanço de pagamentos que possibilita estimular a demanda doméstica (aumento do crédito, elevação do salário mínimo e programas sociais que estimulam o consumo, por exemplo), resultando em estímulo ao crescimento sem fortes impactos no balanço de pagamentos e na dívida externa. Depois de 2008, quando os preços dos produtos básicos registraram uma queda devido à crise financeira mundial, o país pôde expandir seus gastos como medida de estímulo, justamente com base nas poupanças fiscais acumuladas, demonstrando os benefícios de contar com a capacidade de aplicar políticas fiscais anticíclicas, que reduziram o impacto da crise financeira de 2008 (CEPAL, 2013).

Os maiores aumentos do consumo foram no Rio Grande do Norte, Alagoas, Sergipe, Espírito Santo e Mato Grosso (os mesmos estados que aumentaram muito o investimento). Em contrapartida, no segundo ciclo de preços esses estados reduziram o consumo mais do que a média do Brasil.

\subsection{Efeito-Quantum}

O segundo efeito principal a ser apresentado é o efeito-quantum nas exportações e importações para outros estados que também são exportadores de commodities (tabela 03). Esse efeito é indireto e depende da existência de relações comerciais consolidadas entre as regiões que se beneficiam com a valorização dos preços das commodities. Como pode ser observado, o aumento na demanda externa pelas commoditites proporciona um efeito positivo na economia e, portanto, aumenta a demanda pelos produtos e serviços não exportáveis. 
Tabela 03 - Efeito-Quantum: Exportação e Importação Domésticas (2005-2011 e 2011-2014)

\begin{tabular}{|c|c|c|c|c|c|}
\hline \multirow{2}{*}{ Região } & \multirow{2}{*}{ Estados } & \multicolumn{2}{|c|}{ Exportação } & \multicolumn{2}{|c|}{ Importação } \\
\hline & & $2005-2011$ & 2011-2014 & $2005-2011$ & 2011-2014 \\
\hline \multirow{7}{*}{ Norte } & Rondônia & 0,370 & $-0,230$ & $-0,270$ & 0,150 \\
\hline & Acre & 0,620 & $-0,070$ & $-0,510$ & 0,190 \\
\hline & Amazonas & 1,440 & $-0,460$ & $-0,290$ & 0,010 \\
\hline & Roraima & 0,540 & $-0,100$ & $-0,070$ & 0,050 \\
\hline & Pará & 0,320 & $-0,150$ & 1,100 & $-1,080$ \\
\hline & Amapá & 1,670 & $-0,830$ & $-0,300$ & $-0,170$ \\
\hline & Tocantins & 0,610 & $-0,270$ & 0,400 & 0,190 \\
\hline \multirow{9}{*}{ Nordeste } & Maranhão & 0,670 & $-0,450$ & $-0,030$ & 0,290 \\
\hline & Piauí & 0,650 & $-0,280$ & 0,090 & $-0,110$ \\
\hline & Ceará & 0,920 & $-0,430$ & $-0,130$ & $-0,010$ \\
\hline & Rio Grande do Norte & 5,400 & $-1,570$ & 2,540 & $-0,870$ \\
\hline & Paraíba & 1,270 & $-0,610$ & 0,350 & $-0,300$ \\
\hline & Pernambuco & 0,930 & $-0,410$ & 6,750 & $-1,970$ \\
\hline & Alagoas & 1,140 & $-0,580$ & 1,850 & $-1,250$ \\
\hline & Sergipe & 4,350 & $-1,350$ & 2,190 & $-0,820$ \\
\hline & Bahia & 1,620 & $-0,470$ & 3,010 & $-0,920$ \\
\hline \multirow{4}{*}{ Sudeste } & Minas Gerais & 0,760 & $-0,280$ & 2,610 & $-1,400$ \\
\hline & Espírito Santo & 1,220 & $-0,430$ & 3,820 & $-1,910$ \\
\hline & Rio de Janeiro & 1,860 & $-0,710$ & 0,780 & $-0,530$ \\
\hline & São Paulo & 0,940 & $-0,330$ & 0,520 & $-0,370$ \\
\hline \multirow{3}{*}{ Sul } & Paraná & 0,840 & $-0,350$ & 0,800 & $-0,270$ \\
\hline & Santa Catarina & 0,740 & $-0,260$ & $-0,010$ & 0,180 \\
\hline & Rio Grande do Sul & 1,100 & $-0,380$ & $-0,040$ & 0,100 \\
\hline \multirow{4}{*}{ Centro-Oeste } & Mato Grosso do Sul & 0,820 & $-0,480$ & 1,300 & 0,140 \\
\hline & Mato Grosso & 0,480 & $-0,910$ & 2,750 & 0,360 \\
\hline & Goiás & 0,550 & $-0,440$ & 1,080 & 0,260 \\
\hline & Distrito Federal & 0,510 & $-0,140$ & $-0,190$ & 0,050 \\
\hline BRASIL & & 3,790 & $-1,150$ & 4,420 & $-1,400$ \\
\hline
\end{tabular}

Fonte: Elaboração própria.

Os resultados sobre o efeito-quantum permitem observar os efeitos propulsores ("spread effects") e os que agem em direção contrária ("backwash effects"), em conformidade com discussões desenvolvidas por Myrdal (1957) e Hirschman (1958). Ou seja, são os ganhos obtidos pelas regiões por meio do fornecimento de bens de consumo e/ou matérias-primas para as regiões em expansão. Se tal expansão é forte o suficiente para cobrir os efeitos de polarização dos centros mais antigos, novos centros econômicos surgem. Porém, de acordo com os padrões apresentados pelas diferentes regiões ${ }^{13}$ a partir da análise conjunta das exportações e importações domésticas (mapas 05 e 06), as exportações de commodities, em geral, são fracas geradoras de efeitos de transbordamento, não sendo capazes de conferir um impulso dinâmico significativo para o desenvolvimento da economia.

É importante observar, como o fazem Haddad e Perobelli (2002), que para os estados brasileiros as vendas domésticas superaram, em diferentes magnitudes, as exportações internacionais. Além disso, os fluxos interestaduais possuem importância relativamente maior para os estados menos desenvolvidos.

A região Norte apresenta elevado grau de dependência em relação ao Sudeste no que se refere à aquisição de produtos, notadamente o estado do Amazonas (Zona Franca de Manaus). E essa dependência ocorre, principalmente, em relação ao estado de São Paulo, gerando resultados que demonstram um direcionamento dos fluxos para a região Sudeste e Sul. Observa-se pouca integração com o Nordeste e Centro-Oeste para a maioria dos estados da região. Além disso, internamente à região Norte, há fraca interação comercial regional.

Em relação ao Nordeste, tem-se que os estado dessa região dependem muito mais do restante da economia como fonte de aquisição de bens do que o contrário. Assim como no caso da região Norte, a dependência em relação ao Sudeste é grande, com destaque para São Paulo e Minas Gerais. Ao mesmo tempo, a região Sudeste também é o principal comprador dos estados do Nordeste.

Os resultados para o Sudeste, que é a região mais integrada de todas, corroboram a ideia de que os estados menores dependem em maior grau do resto da economia brasileira do que os estados

\footnotetext{
${ }^{13}$ Esses padrões, em grande medida, corroboram as conclusões obtidas por Perobelli (2004).
} 
maiores. Os insumos utilizados no Sudeste são encontrados, em quantidade considerável, dentro da própria região ou importados do resto do mundo. Os próprios estados da região Sudeste são o principal mercado de aquisição de produtos, havendo uma concentração de fluxos intra-regionais. São Paulo se destaca como polarizador desse processo (PEROBELLI, 2004). Os resultados evidenciam o papel concentrador dos fluxos de comércio, tanto pela concentração na região mais desenvolvida do país como pela dependência das regiões menos desenvolvidas. É o que Haddad (2004) chama de "armadilha espacial", polarizada por São Paulo. Este centro de gravidade funciona, no curto prazo, como ponto de convergência devido à melhor acessibilidade dos mercados, gerando os maiores impactos em termos de eficiência. No longo prazo, os movimentos de realocação do capital e trabalho também parecem fortalecer essa concentração (MAGALHÃES, 2009).

A região Sul apresenta uma forte interação entre os seus estados, o que torna a região uma importante fonte de aquisição de bens para estes estados. E a região Centro-Oeste, no que tange à aquisição de bens, é mais dependente do resto da economia brasileira do que o contrário. A região Sudeste é o principal mercado para a aquisição de bens dos estados do Centro-Oeste, enquanto os fluxos em direção ao Norte e ao Nordeste ainda são incipientes.

Mapa 05 - Variação Anual das Exportações Domésticas

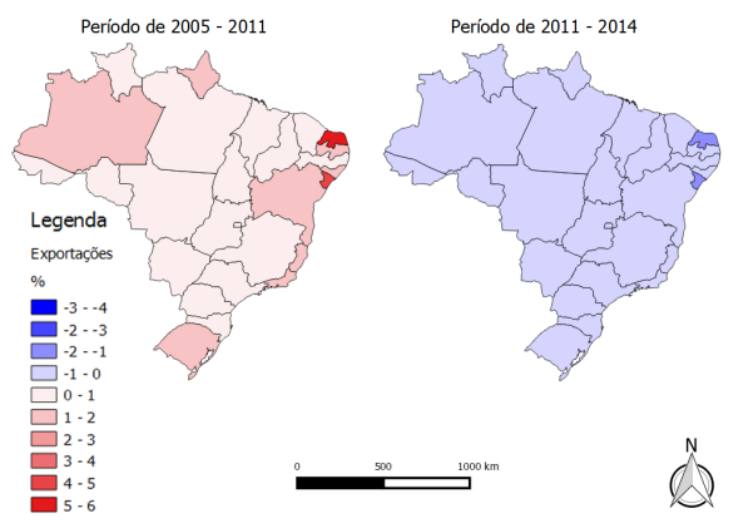

Mapa 06 - Variação Anual das Importações Domésticas

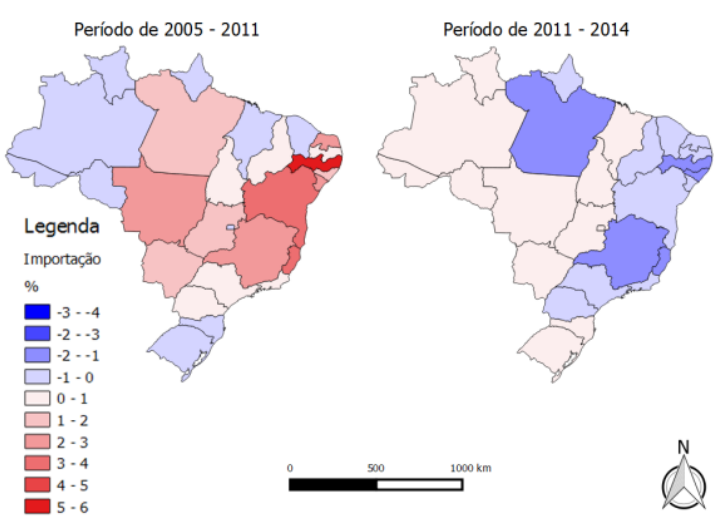

Fonte: Elaboração própria.

Observa-se que, em geral, a estrutura produtiva do Brasil tem limitado os possíveis benefícios advindos dos impulsos dinâmicos da demanda mundial e da demanda interna. $\mathrm{O}$ comportamento de certas regiões não está intimamente ligado ao desempenho nos mercados internacionais, mas sim à articulação com as demais regiões e, mais especificadamente, dos estados em termos do mercado doméstico (HADDAD e PEROBELLI, 2002).

Para alguns estados, as exportações crescem mais que as importações, no primeiro período, indicando que o ciclo de preços das commodities tem estimulado a diminuição da dependência regional. Isso é importante porque diminui o vazamento de poupança das regiões periféricas. Para outros estados, as importações domésticas (que são mais sensíveis em relação à renda) crescem mais rapidamente que as exportações regionais, razão pela qual quando as regiões aceleram seu crescimento surgem desequilíbrios que freiam o impulso expansivo. Esse é o caso dos estados do Pará, Pernambuco, Alagoas, Bahia, Minas Gerais, Espírito Santo e de quase toda a região CentroOeste. Dessa forma, os superávits de algumas regiões são utilizados para financiar as importações de outras regiões, beneficiando estas últimas. Como as regiões mais dinâmicas não são autossuficientes, o comércio funciona como meio de transmissão de crescimento, pois parte da riqueza gerada na região é gasta em outra região complementar. As entradas de capitais podem financiar esses desequilíbrios, porém, no longo prazo, o crescimento será sustentável apenas se houver uma mudança na estrutura produtiva.

\subsection{PIB Regional}

A partir dos dois efeitos apresentados (efeito-preço e efeito-quantum), parte-se para a análise agregada do PIB das regiões, que é impactado diretamente pelo aumento das vendas externas e, indiretamente, a partir de um multiplicador keynesiano da renda, do consumo e do investimento (HADDAD e GRIMALDI, 2011). Em relação ao produto (PIB real), os resultados podem ser vistos na tabela 04 e no mapa 07. 
Tabela 04 - Variação Anual do PIB (Simulação), do Crescimento Real e ICDC (2005-2011 e 2011-2014)

\begin{tabular}{|c|c|c|c|c|c|c|c|}
\hline \multirow{2}{*}{ Região } & \multirow{2}{*}{ Estados } & \multicolumn{2}{|c|}{ PIB (Simulação) } & \multicolumn{2}{|c|}{ Crescimento Real } & \multicolumn{2}{|c|}{ ICDC } \\
\hline & & $2005-2011$ & 2011-2014 & $2005-2011$ & 2011-2013 & $2005-2011$ & 2011-2013 \\
\hline \multirow{7}{*}{ Norte } & Rondônia & 0,000 & 0,030 & 7,50 & $-0,36$ & 0,00 & $-8,37$ \\
\hline & Acre & $-0,120$ & 0,090 & 5,53 & 0,46 & $-2,17$ & 19,38 \\
\hline & Amazonas & 0,540 & $-0,210$ & 4,66 & 1,69 & 11,59 & $-12,41$ \\
\hline & Roraima & 0,280 & $-0,050$ & 7,48 & 2,44 & 3,74 & $-2,05$ \\
\hline & Pará & 1,140 & $-0,610$ & 7,60 & 5,69 & 15,00 & $-10,71$ \\
\hline & Amapá & 0,150 & $-0,280$ & 6,34 & 5,36 & 2,37 & $-5,22$ \\
\hline & Tocantins & 0,490 & 0,000 & 5,12 & 1,26 & 9,56 & 0,00 \\
\hline \multirow{9}{*}{ Nordeste } & Maranhão & 0,340 & 0,060 & 7,04 & 4,13 & 4,83 & 1,45 \\
\hline & Piauí & 0,310 & $-0,140$ & 7,75 & 2,24 & 4,00 & $-6,24$ \\
\hline & Ceará & 0,190 & $-0,090$ & 6,83 & 1,77 & 2,78 & $-5,09$ \\
\hline & Rio Grande do Norte & 2,620 & $-0,830$ & 6,24 & 6,55 & 41,99 & $-12,68$ \\
\hline & Paraíba & 0,540 & $-0,300$ & 6,58 & 3,08 & 8,21 & $-9,75$ \\
\hline & Pernambuco & 0,420 & $-0,260$ & 6,70 & 3,77 & 6,27 & $-6,90$ \\
\hline & Alagoas & 1,300 & $-0,780$ & 5,38 & 4,73 & 24,18 & $-16,47$ \\
\hline & Sergipe & 2,490 & $-0,840$ & 4,87 & 3,62 & 51,08 & $-23,19$ \\
\hline & Bahia & 0,940 & $-0,200$ & 3,68 & $-0,20$ & 25,53 & 100,00 \\
\hline \multirow{4}{*}{ Sudeste } & Minas Gerais & 1,360 & $-0,660$ & 5,09 & 1,46 & 26,72 & $-45,27$ \\
\hline & Espírito Santo & 3,330 & $-1,640$ & 7,14 & 2,40 & 46,64 & $-68,36$ \\
\hline & Rio de Janeiro & 0,960 & $-0,420$ & 4,17 & 5,28 & 23,00 & $-7,95$ \\
\hline & São Paulo & 0,490 & $-0,140$ & 4,37 & 1,02 & 11,21 & $-13,68$ \\
\hline \multirow{3}{*}{ Sul } & Paraná & 0,500 & $-0,060$ & 3,06 & 5,14 & 16,36 & $-1,17$ \\
\hline & Santa Catarina & 0,170 & $-0,020$ & 5,15 & 1,95 & 3,30 & $-1,03$ \\
\hline & Rio Grande do Sul & 0,170 & 0,000 & 2,67 & $-0,53$ & 6,36 & 0,00 \\
\hline \multirow{4}{*}{$\begin{array}{c}\text { Centro- } \\
\text { Oeste }\end{array}$} & Mato Grosso do Sul & 1,020 & $-0,010$ & 6,38 & 6,48 & 15,99 & $-0,15$ \\
\hline & Mato Grosso & 1,820 & 0,340 & 2,82 & 4,15 & 64,46 & 8,20 \\
\hline & Goiás & 0,650 & $-0,010$ & 6,24 & 5,48 & 10,42 & $-0,18$ \\
\hline & Distrito Federal & $-0,030$ & 0,010 & 6,32 & $-4,56$ & $-0,47$ & $-0,22$ \\
\hline BRASIL & & 0,710 & $-0,240$ & 4,70 & 2,08 & 15,10 & $-11,54$ \\
\hline
\end{tabular}

Fonte: Sistema de Contas Nacionais (IBGE) e Simulações. Elaboração própria.

Legenda:

Crescimento acima da média nacional

Crescimento abaixo da média nacional

No primeiro período (2005-2011), como há crescimento significativo das exportações de commoditites, praticamente todos os estados apresentam variação anual positiva do PIB real. É importante observar que os resultados apresentados indicam apenas a variação do PIB real advinda dos choques das exportações de commodities, em relação ao cenário registrado em 2005, ou seja, não mostram o crescimento efetivamente apurado das regiões no período. O exercício proposto, ao isolar o efeito das commoditites, permite identificar melhor a resposta das regiões ao comportamento do comércio mundial desses bens. Em praticamente todos os estados, o PIB cresce mais que o emprego, o que significa que esse impacto estimula a substituição do trabalho por capital.

Considerando a elevada relação massa/volume das commodities, a via de transporte internacional utilizada para sua exportação é a marítima. Este fato explica em grande medida o impacto no PIB dos estados do Espírito Santo (3,33\% a.a.), Rio Grande do Norte (2,62\% a.a.) e Sergipe (2,49\% a.a.). O Espírito Santo apresenta forte dependência em relação ao setor externo, com uma estrutura produtiva concentrada em um número reduzido de atividades e com produção fortemente destinada ao exterior (minério de ferro, petróleo e gás, celulose e papel). Com o intenso choque das commodities, o PIB real estadual cresce fortemente.

Os resultados de Minas Gerais (1,36\% a.a.) e do Pará (1,14\% a.a.) se explicam, em grande medida, pela estrutura produtiva com vínculos mais sensíveis à evolução da demanda por commodities minerais. Mato Grosso tem impacto significativo $(1,82 \%$ a.a.) pela produção de commodities agrícolas como a soja e seus derivados. São Paulo cresce menos em termos relativos $(0,49 \%$ a.a. $)$, mas, considerando o tamanho da economia paulista, tem-se significativa variação em termos absolutos, especialmente porque o estado é importante elo comercial nacional.

Grande parte dos estados do Nordeste apresenta pouco crescimento em razão das commodities (Maranhão, Piauí, Ceará, Paraíba e Pernambuco), assim como os estados do Sul do país. Além disso, o Acre registra um impacto negativo desse boom no período (-0,12\% a.a.), assim como o Distrito Federal (-0,03\% a.a.), cuja economia é representada em mais de $90 \%$ pelo setor de 
serviços, e, por fim, Rondônia (0,00\% a.a.), que não se beneficia como a ampliação das exportações de commodities, apesar da recente expansão da soja.

A razão para que se observem impactos distintos do boom das commodities está no fato de que a produção desses bens está distribuída de forma desigual no território e, a depender da integração econômica dos estados e da intensidade dos fluxos comerciais, esses impactos podem se concentrar espacialmente.

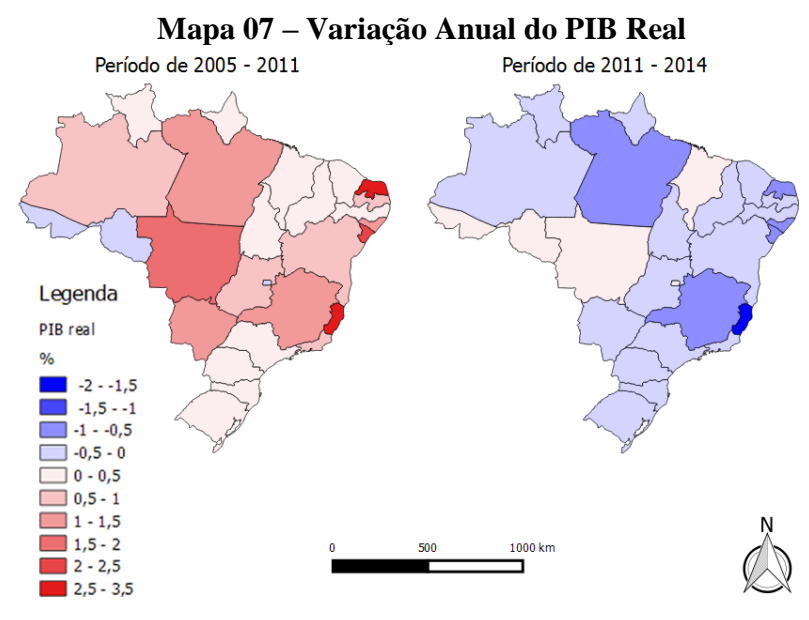

Fonte: Elaboração própria.

No segundo período (2011-2014), como houve queda nas exportações de várias commoditites, os resultados negativos foram bastante generalizados, basicamente pelas mesmas razões que explicam o impacto positivo durante o primeiro período. Isso mostra como muitos estados dependem fortemente da exportação de commodities.

Os estados que apresentaram os maiores impactos positivos no primeiro período também são os que apresentam maior perda com a queda das exportações de commoditites: Espírito Santo, devido à forte concentração da estrutura produtiva, Rio Grande do Norte e Sergipe. Minas Gerais e Pará respondem basicamente pela queda do minério. São Paulo é afetado negativamente e os estados do Maranhão, do Acre e de Rondônia, que pouco responderam ao boom observado em 2005-2011, também pouco se influenciaram com as variações em 2011-2014.

Em termos dos impactos desiguais dos choques nas exportações de commoditites, é importante observar que o impulso no crescimento do PIB real durante o primeiro período dura mais tempo e tem maior intensidade (maiores taxas) quando comparado ao segundo período. Assim, temse que os efeitos do primeiro são mais intensos que o do segundo, ou seja, a tendência de crescimento desigual via commoditites em 2005-2011 não é suplantada em 2011-2014.

Por meio dos dados do PIB é possível identificar se há, exclusivamente pelo movimento das commodities, uma tendência de convergência ou divergência entre as economias estaduais. Seguindo ideia já amplamente difundida na literatura, a convergência ocorre quando regiões menos avançadas crescem a taxas superiores às das regiões mais desenvolvidas, ocorrendo uma aproximação da média, reduzindo o grau de desigualdade inter-regional. Em sentido oposto, a divergência ocorre quando as regiões menos avançadas crescem a taxas menores, resultando em afastamento da média, ampliando o grau de desigualdade inter-regional.

Na simulação, pode-se dizer que o efeito das commodities não é no sentido de convergência para vários estados do Norte, Nordeste, Sul e Centro-Oeste, pois eles crescem abaixo da média nacional. A exceção mesmo ocorre nos estados produtores de commodities. Ou seja, esse ciclo de expansão estimula a divergência entre os estados. No segundo ciclo, de queda, essa tendência é parcialmente atenuada. Mas para vários estados do Nordeste, a redução é maior que a média, ou seja, esses estados tendem a piorar suas posições relativas. Isso acontece também com quase todos os estados do Sudeste, exceto São Paulo. Esse ciclo de commodities vai ao encontro das ideias de polarização de Myrdal, uma vez que os efeitos propulsores (ou de espraiamento) provocados em algumas regiões não são capazes de reverter o processo de concentração.

É interessante fazer essa mesma análise com os dados do PIB real total, que foi o crescimento efetivamente ocorrido nos estados, e não apenas o advindo das commodities. A partir 
desses dados observa-se que quase todos os estados do Norte, Nordeste e Centro-Oeste crescem mais que a média nacional, indicando convergência. Com isso, conclui-se que outros fatores econômicos suplantaram os efeitos dos ciclos de commodities, indicando que as economias desses estados não são tão dependentes assim desses ciclos. Ou seja, dada a estrutura de comércio interestadual, conclui-se que o crescimento econômico das regiões talvez não esteja intimamente ligado a especializações produtivas e às exportações de commodities. Mesmo assim, apesar do crescimento do PIB com crescimento mais rápido das regiões mais pobres, a convergência ainda parece bastante lenta. No segundo período essa tendência se mantém parcialmente.

A tese clássica do estruturalismo é a de que a especialização na produção de commodities implicaria num menor dinamismo das economias especializadas. Essa tese foi proposta contemporaneamente por Hausmann (2007), que afirmou que o baixo dinamismo advém dos reduzidos encadeamentos produtivos, com diminuição dos efeitos multiplicadores e aceleradores, da estagnação relativa do progresso técnico e a uma baixa irradiação (spillover) para o conjunto da economia (CARNEIRO, 2012). Aqui os dados parecem corroborar apenas parcialmente essa tese, se aproximando mais das contestações feitas por Sinott (2010) às ideias de Hausmann (2007).

Como forma de analisar a dependência que os estados têm do comércio de commoditites, propõe-se neste artigo o cálculo de um indicador referente ao crescimento regional dependente das commoditites. O ICDC (Índice de Crescimento Dependente de Commodities) mede peso do crescimento via commodities no crescimento real efetivamente observado dos estados, como segue:

$$
I C D C=\frac{C C}{C R T}
$$

Em que:

CC: Crescimento do PIB real via commodities (taxa anual), obtido nas simulações;

CRT: Crescimento real total efetivamente apurado (taxa anual).

A tabela 04 também apesenta os valores do $\mathrm{ICDC}^{14}$ para cada estado nos dois períodos de análise. O ICDC do país, no primeiro período, indica que $15,10 \%$ do crescimento real da economia brasileira se devem ao comportamento das commodities. O elevado grau de dependência do crescimento pode ser observado para vários estados do Nordeste (Sergipe e Rio Grande do Norte, em especial), do Sudeste (Espírito Santo e Minas Gerais) e do Centro-Oeste (Mato Grosso).

Para o segundo período, o Brasil apresenta um ICDC de $-11,54 \%$, o que significa que as variações provocadas pelas commoditites equivalem, em magnitude, a $11,54 \%$ das variações efetivamente observadas, mas, nesse caso, no sentido inverso, ou seja, de puxar o crescimento real para baixo. Os índices mais expressivos são os da Bahia, que registrou um PIB real negativo e um ICDC equivalente a $100 \%$, o que implica dizer que a totalidade ${ }^{15}$ da variação observada se deve aos efeitos diretos e indiretos do comportamento das commoditites (o indicador é positivo em razão das duas variações terem ocorrido na mesma direção, neste caso de diminuição). Além disso, Espírito Santo e Minas Gerais se destacam pela significativa dependência de suas economias.

A reposta desigual de algumas regiões pode ser constatada pelo fato de que a razão de dependência de commoditites de alguns estados é maior no primeiro período do que no segundo, ou seja, são estados que parecem se beneficiar mais dos choques positivos do que perder com a retração do comércio internacional desses bens (Rio Grande do Norte, Sergipe e Mato Grosso). Nos casos do Espirito Santo e de Minas Gerais a tendência é oposta, de forma que a participação da queda das commodities é superior à parcela causada por seu crescimento.

\section{Conclusão}

A economia brasileira apresentou respostas significativas ao efeito-preço das exportações de commodities (investimento, emprego regional, renda e consumo), ao efeito-quantum nas exportações para outras regiões exportadoras de commodities (exportação e importação domésticas) e ao resultado agregado do PIB. Essas informações revelam que, nos ciclos econômicos recentes, as

\footnotetext{
${ }_{14}^{14}$ Apesar das simulações neste trabalho compreenderem o período 2005-2014, o ICDC é calculado para 2005-2011 e para 20112013, pois os dados do PIB regional só estão disponíveis até este ano.

${ }^{15}$ Considerando os procedimentos numéricos para obtenção de soluções para os modelos de EGC, as magnitudes relativas e os sinais encontrados são mais relevantes para as análises do que os valores exatos extraídos do modelo.
} 
regiões brasileiras seguem a mesma configuração: crescendo quando cresce a economia nacional, em seu conjunto, e desacelerando-se quando o país reduz seu crescimento. No entanto, isso ocorre com regiões registrando taxas distintas, resultando em concentração econômica no Sudeste e num tímido processo de desconcentração em outras poucas regiões. Para as regiões muito dependentes das commodities, o principal efeito da volatilidade dos preços é a redução das taxas de investimento e do crescimento em longo prazo. Essas constatações reforçam a tese defendida por Gruss (2014) de que o que tem sido mais relevante para o crescimento econômico das regiões exportadoras de commodities não é o nível dos preços reais desses produtos, mas sim sua taxa de crescimento. $\mathrm{Ou}$ seja, o problema do crescimento econômico dessas regiões é sua dependência do crescimento permanente dos preços das commodities, exigindo novos choques favoráveis nos preços para que a atividade econômica não perca fonte de dinamismo, pois os efeitos multiplicadores a partir do comércio externo são temporários.

As tendências observadas refletem uma concentração econômica (seletiva setorial e espacialmente), que não tem permitido, aparentemente, reduzir as desigualdades regionais. Mantémse forte desigualdade intra e inter-regional e o processo de desconcentração espacial iniciado nas últimas décadas tem sido restrito e parece perder fôlego para reverter o alto grau de desigualdade existente na economia nacional (DINIZ, 2013). Embora possa existir uma tendência à convergência entre as regiões, esta convergência é lenta e tende a se estabilizar num patamar de grande heterogeneidade (surgimento de "ilhas de produtividade"), além da permanência da concentração econômica no Centro-Sul do país e uma grande dependência do Norte e Nordeste em relação a esta região. Além disso, o comportamento de certas regiões não está intimamente ligado ao desempenho nos mercados internacionais, mas sim à articulação com as demais regiões, e mais especificadamente, dos estados em termos do mercado doméstico.

A questão colocada para muitos estados brasileiros está no baixo potencial de upgrading das atividades primárias em direção ao maior valor adicionado dos produtos, sua baixa capacidade de spillover e fraco encadeamento com outras atividades produtivas domésticas (CEPAL, 2014). São, em geral, as mesmas ideias apontadas por Hirschman de que as commodities são fracas geradoras de efeitos de transbordamento, não sendo capazes de conferir um impulso dinâmico significativo para o desenvolvimento da economia. Aspectos estruturais da economia brasileira indicam que as exportações não constituem uma fonte relevante e permanente de impulso ao crescimento, pois à medida que o crescimento doméstico acelera e, principalmente, o investimento começa a aumentar, as importações crescem mais rápido que o PIB.

A análise dos impactos exclusivos do ciclo das commodities permite concluir que esse movimento tende a reforçar uma trajetória de concentração espacial ou de acirramento de desigualdades regionais, a exemplo das ideias de base de exportação de North, mas agora num contexto de maior inserção do país e das regiões na economia mundial e de maiores dificuldades dos Estados em compensar os custos sociais de uma maior desigualdade regional (MACEDO e MORAIS, 2011). Em resumo, ainda permanece a discussão sobre os estímulos ao crescimento regional como forma de diminuir as desigualdades ainda existentes e a forma como as regiões brasileiras estão inseridas na economia mundial.

\section{Referências}

ANP - Agência Nacional do Petróleo, Gás Natural e Biocombustíveis (2014). Dados Estatísticos Mensais. Disponível em: 〈http://www.anp.gov.br〉. Acesso em: 15 jun. 2014.

BLACK, C. Eventos relacionados ao superciclo de preços das commodities no século XXI. Indicadores Econômicos FEE, Porto Alegre, v. 40, n. 2, p. 67-78, 2013.

Preços de commodities, termos de troca e crescimento econômico brasileiro nos anos 2000.

Indicadores Econômicos FEE, Porto Alegre, v. 42, n.3, p. 27-44, 2015.

BRASIL. MINISTÉRIO DO DESENVOLVIMENTO, INDÚSTRIA E COMÉRCIO EXTERIOR (MDIC). Estatísticas da Secretaria de Comércio Exterior (SECEX). Brasília, 2015. Disponível em: <http://www.desenvolvimento.gov.br/>. Acesso em: 15 dez. 2015.

BURKHARD, J. The price of oil: a reflection of the world. Testimony before the Senate Committee on Energy and Natural Resources. Washington DC: US Senate, 2008.

CANO, W. Raízes da concentração industrial em São Paulo, Difel, São Paulo, 1977. 
. Concentração e desconcentração econômica regional no Brasil: 1970/95. Economia e Sociedade, v. 8, jun., p. 101-141. 1997.

CARLEIAL, L. A contribuição neoschumpeteriana e o desenvolvimento regional. In: CRUZ, B. et al. (Org.). Economia regional e urbana: teorias e métodos. Brasília: Ipea, 2011.

CARNEIRO, R. M. Commodities, choques externos e crescimento: reflexões sobre a América Latina. Santiago do Chile: Cepal, 2012.

CEPAL - Comissão Econômica para a América Latina e o Caribe. Recursos naturais: situação e tendências para uma agenda de desenvolvimento regional na América Latina e no Caribe. Publicação das Nações Unidas (LC/L.3748). Santiago, Chile, 2013.

Mudança estrutural para a igualdade Uma visão integrada do desenvolvimento. Publicação das Nações Unidas LC/G.2604. Santiago, Chile, 2014.

DINIZ, Célio Campolina. Desenvolvimento poligonal no Brasil: nem desconcentração nem contínua polarização. Nova Economia, v.3, n.1. Belo Horizonte, UFMG/FCE/DCE. 1993.

A Dinâmica Regional Recente da Economia Brasileira e suas Perspectivas. Texto para Discussão, IPEA. n. 375, jun. 1995.

A questão regional e as políticas governamentais no Brasil. Belo Horizonte: Cedeplar, Face, UFMG, 2001. (Texto para discussão n.159).

Dinâmica Regional e Ordenamento do Território Brasileiro: desafios e oportunidades. Belo Horizonte: Cedeplar, Face, UFMG, 2013. (Texto para discussão n.471).

DINIZ, C. C.; CROCCO, M. A. Reestruturação econômica e impacto regional: o novo mapa da indústria brasileira. Nova Economia, 6, p. 77-103, 1996.

DIXON, P. B.; PARMENTER B. R.; SUTTON, J. M.; VINCENT D. P. ORANI: A Multisectoral Model of the Australian Economy. Amsterdam: North-Holland, 1982. 372 p.

DOMINGUES, E. P. Dimensão regional e setorial da integração brasileira na Área de Livre Comércio das Américas. (Tese de doutorado) IPE/USP, SP, 2002.

FAO. The state of the agricultural commodity markets. Disponível em: <www.fao.org>. 2009.

FERCHEN, M. As Relações entre China e América Latina: Impactos de Curta ou Longa Duração?

Revista de Sociologia Política, Curitiba, v. 19, p. 105-130, nov. 2011.

FERREIRA. Condições externas e a dinâmica da inflação no Brasil 1994-2010: uma interpretação estrutural. 160 f. 2012. Tese (Doutorado em Economia), Instituto de Economia - IE. UFRJ, 2012.

FERREIRA FILHO, J. B. S. Introdução aos Modelos Aplicados de Equilíbrio Geral: Conceitos, Teoria e Aplicações. In: CRUZ, B. et al. (Org.). Economia regional e urbana: teorias e métodos. Brasília: Ipea, 2011. cap. 12. parte II. p. 375-400.

FURTADO, C. (1976). Formação econômica do Brasil, São Paulo, Editora Nacional.

GUILHOTO, J. J. M. Análise de Insumo-Produto: Teoria, Fundamentos e Aplicações. FEA-USP. Versão Revisada. 2011. Disponível em: <http://ideas.repec.org>. Acesso em: 15 jun. 2014.

GUIMARÃES NETO, L. Desigualdades e políticas regionais no Brasil: caminhos e descaminhos. Planejamento e Políticas Públicas, IPEA, Brasília, n.15, jun., p.41-95. 1997.

GURGEL, A. C. Modelo de Equilíbrio Geral. Economia de Baixo Carbono: Avaliação de Impactos de Restrições e Perspectivas Tecnológicas. Núcleo de Estudos em Economia de Baixo Carbono. Ribeirão Preto, SP, 2012. 185 p.

GRUSS, B. After the boom-commodity prices and economic growth in Latin America and the Caribbean. [S.1.]: IMF, 2014. (IMF Working Papers, n. 154).

HADDAD, P. R. Tendências recentes do comércio internacional e suas implicações para a economia de minas. Cadernos BDMG. Belo Horizonte, n.6, p. 4 - 63. Fev. 2003.

HADDAD, E. A. Retornos Crescentes, Custos de Transporte e Crescimento Regional. São Paulo. (Tese de Livre Docência em Economia). IPE/USP, 2004. 207 p.

HADDAD, E. A., GRIMALDI, D. Impactos sistêmicos do padrão de especialização do comércio exterior brasileiro. Brasília: CEPAL/IPEA, 2011. (Textos para Discussão, 41).

HADDAD, E. A.; HEWINGS, G. J. D. Market Imperfections in a Spatial Economy: Some Experimental Results. The Quarterly Review of Economics and Finance, n. 45, 2005. 
HADDAD, E. A.; PEROBELLI, F. S. Integração regional e padrão de comércio dos estados brasileiros. In: KON, Anita (Org.). Unidade e fragmentação: a questão regional no Brasil. São Paulo: Perspectiva, 2002. p. 221-246.

HAUSMANN, R. Hwang, J. Rodrik, D. What you export matters. Journal of Economic Growth, 2007. HIRSCHMAN, A. O. Estratégia do desenvolvimento econômico. Rio de Janeiro: Fundo de Cultura, 1961. Edição original de 1958.

HORRIDGE, M.; MADDEN, J.; WITTWER, G. The impact of the 2002-2003 drought on Australia. Journal of Policy Modeling, New York, v. 27, n. 3, p. 285-308, Apr., 2005.

LEMOINE, F.; KESENCI-ÜNAL, D. (2002) "Chine: spécialisation internationale et rattrapage technologique". Économie International. 4 (92): 11-40.

LEONTIEF, W. et al. The Economic Impact - Industrial and Regional - Of An Arms Cut. The Review of Economic Statistics. 47(3): 217-241, 1965.

MACEDO, F. C. de, MORAIS, J. M. L. Inserção comercial externa e dinâmica territorial no Brasil: especialização regressiva e desconcentração produtiva regional. Informe Gepec, Toledo, v. 15, n. 1, p. 82-98, jan./jun. 2011.

MAGALHÃES, A. S. O comércio por vias internas e seu papel sobre crescimento e desigualdade regional no Brasil. (Mestrado em Economia) - Centro de Desenvolvimento e Planejamento Regional da Universidade Federal de Minas Gerais, Belo Horizonte, 2009.

MAYERS, J. The financialization of commodity market and commodity price volatility. [A. do livro] S. Kotte, D. Márquez, A. Priewe, J. Dullien. The Financial and Economic Crisis of 2008-2009 and Developing Countries. Genève: UNCTAD, 2010.

MONASTERIO, L. M.; CAVALCANTE, L. R. Fundamentos do pensamento econômico regional. In: Cruz, B. O.; Furtado, B.A; Monasterio, L.; Rodrigues Jr., W. (Org.). Economia regional e urbana: teorias e métodos com ênfase no Brasil. 1 ed. Brasília: IPEA, 2011.

MYRDAL, G. Teoria econômica e regiões subdesenvolvidas. Belo Horizonte: Biblioteca Universitária - UFMG, 1960. Edição original de 1957.

NORTH, D. C. Teoria da localização e crescimento econômico regional. In: Schwartzman, J. Economia regional: textos escolhidos. Cedeplar, Belo Horizonte, 1977.

PACHECO, C. A. Novos Padrões de Localização Industrial? Tendências Recentes dos Indicadores de Produção e do Investimento Industrial. Texto para Discussão, IPEA, n. 633, 1999.

PEROBELli, F. S. Análise das Interações Econômicas entre os Estados Brasileiros. (Tese de Doutorado). São Paulo: Universidade de São Paulo, 2004. 246 p.

PERROUX, F. O conceito de pólo de desenvolvimento. In: SCHWARTZMAN, J. (Org.). Economia regional: textos escolhidos. Belo Horizonte: Cedeplar, 1977. Original de 1955.

PRATES, D. M. A alta recente dos preços das commodities. Revista de Economia Política, São Paulo, v. 27, n. 3, p. 323-344, jul./set. 2007.

SERRANO, F. A mudança na tendência dos preços das commodities nos anos 2000: aspectos estruturais. Revista Oikos, Rio de Janeiro, v. 12, n. 2, p. 168-198, 2013.

SINOTT, E. N., J. de la Torre, A. Natural Resources in Latin American and the Caribean: Beyond Booms and busts. Washington: The World Bank, 2010.

WILTGEN, R. S. Notas sobre Polarização e Desigualdades Regionais. Ensaios FEE, Porto Alegre, v. 12, n. 2, p.532-539, 1991. 